\title{
A comparative assessment of chemical stabilisers including waste materials, for the treatment of swelling-shrinking soils
}

\author{
Maria Mavroulidou ${ }^{1, *}$, Christopher Gray $^{2}$, Fortunate Gumbochuma ${ }^{1,2}$ and Michael J. Gunn ${ }^{1}$ \\ ${ }^{1}$ London South Bank University, 103 Borough Road, SE1 0AA London, UK \\ ${ }^{2}$ Hertfordshire County Council, County Hall, Pegs Lane, Hertford, SG13 8DE, UK
}

\begin{abstract}
This paper assesses comparatively the performance of a number of innovative soil stabilisers for the treatment of a highly swelling-shrinking soil, against that of commercial calcium lime. The production of lime, a most common soil stabiliser, involves high energy consumption, carbon dioxide emissions and the depletion of natural raw materials. Alternatives are actively sought, in particular industrial wastes and byproduct materials or lower energy demand cements e.g. reactive magnesia $(\mathrm{MgO})$ cements. In this paper calcium lime, reactive magnesia, industrial wastes and mixes of these with lime are comparatively assessed, based on a number of conventional measures of the propensity of a soil to swell, i.e. plasticity characteristics and swelling characteristics (swelling strains, swelling pressures, swelling indices). Furthermore, as expansive soils are typically in an unsaturated state hence sensitive to both changes in water content and suction, filter paper testing was performed to provide additional evidence of the effect of the treatments on the swelling/shrinking soil. According to the main findings, for the treatment of swelling shrinking soils, binders coming from the paper recycling industry show most promise as alternatives to lime; reactive magnesia cement had a smaller effect than calcium based stabilisers in improving the swelling-shrinking of the soil, yet it also suppressed swelling and shrinkage considerably; it thus shows potential for use as an alternative to common soil stabilisers (Portland cement and calcium lime) to alleviate the environmental impact of the latter.
\end{abstract}

\section{Introduction}

Soils that experience very considerable volume changes upon changes in moisture content are classified as swelling-shrinking soils (also known as expansive soils). These soils cause major damages to lightweight structures, pavements, slopes and utilities and financial losses reported to exceed those caused by other natural disasters such as such as earthquakes or tornadoes [1]. Due to the severity of the problem, this type of soil has been the focus of considerable research. Part of this concerns stabilisation with chemical agents such as lime, successfully used to improve the engineering properties of expansive clayey soils by changing their mineralogy and hence reducing their propensity for volume changes upon moisture changes. Reviews of such research can be found in [2]. Whilst the use of commercially produced chemical stabilisers such as lime has been established, an increased environmental awareness urges engineers to consider the potential use of alternative stabilisers, originating from waste materials and/or binders of lower energy demand for their production, such as calcined magnesia cements. This paper thus assesses the potential of treating a highly expansive soil using (a) the latter type of cement; (b) one industrial by-product (of steel production) namely Ground Granulated Blast Furnace
Slag (GGBS) and (c) one waste material Paper Sludge Ash (PSA) as well as mixtures of these, partly or fully replacing commercial hydrated lime, which used as benchmark for other stabilisers (i.e. mixes of limeGGBS, lime-PSA and PSA-GGBS). PSA is produced by the incineration of paper mill sludge, a by-product of the deinking and re-pulping of paper, in controlled heat and power (CHP) plants. Paper sludge and the resulting ash from its incineration are becoming abundant in the UK, as paper recycling rates are increasing. Recent statistics reported an annual production of ca. 4.5 million tonnes in the UK, leading to steadily increasing amounts of PSA (in the UK 4 out of 40 paper mills generate 140 ktonnes of PSA annually [3]). This has caused environmental concerns and high costs to industry due to UK landfill tax. Both waste paper sludge and paper sludge ash are presently predominantly mostly discarded in landfill. There is therefore a lot of interest in finding outlets for these materials as alternatives to landfilling.

The success of chemical stabilisers of expansive soils has been traditionally evaluated in the laboratory based on their effect on the plasticity characteristics of the soil (a large number of different empirical correlations of the swelling potential and the plasticity characteristics of the soil can be found in the literature). Other ways of assessing the effect of the chemical stabilisers are

Corresponding author: mavroum@1sbu.ac.uk 
measurements of a number of swelling indices, swelling strains and/or swelling pressure of the soil before and after treatment, based on different laboratory tests including standard (i.e. not suction controlled) oedometer testing [4]-[7]. Vanapalli argued that these measurements may not give reliable estimates of heave, as expansive soils are typically in an unsaturated state, hence sensitive to both the changes in water content and as well as suction [8]. This paper thus assesses the performance of the different stabilisers using the common approaches based on plasticity tests and standard (i.e. not suction-controlled) free-swell oedometer tests to assess the one-dimensional swelling strain and swelling pressures but also performs suction measurements using contact filter paper tests to determine the Soil Water Retention Curves (SWRC) and shrinkage curves before and after treatment, giving additional evidence on the positive effect of the chemical additives on the volumetric behaviour of the soil.

\section{Materials and methods}

The expansive soil used in this study was a mix of $50 \%$ Wyoming sodium bentonite and 50\% kaolin clay from the South West of England supplied by Imerys. Tests for the total and water soluble sulphate content based on the gravimetric method of BS 1377-3:1990 [9] showed no evidence of sulphates in the soils; this allows for the use of calcium-based stabilisers, without the risk of claysulphate reactions. Any expansion effects would then be attributed to the original clay mineralogy and in particular the bentonite content. The soil stabilisers used were: (a) a hydrated lime with a relative $\mathrm{Ca}(\mathrm{OH})_{2} / \mathrm{CaO}$ ratio of 4.88/1.00; (b) PSA from Aylesford Newsprint Ltd. (Kent, UK); (c) ground granulated blast furnace slag (GGBS) from Hanson-Regen; (d) reactive magnesia cement i.e. calcined magnesite containing a minimum of $94 \% \mathrm{MgO}$, supplied by Richard Baker Harrison Ltd. The particle size distribution of the tested soils and stabilisers based on hydrometer testing [12] is shown in Figure 1. Typical oxide compositions of the materials based on available suppliers' information are shown in Table 1. For the PSA the chemical composition and free lime contents would vary according to feedstock and combustion conditions [10]. In general, due to high free lime contents PSA has a $\mathrm{pH}=12.3-12.4$, which in fact is the same as that of the hydrated lime used. GGBS has only slow cementitious properties if used on its own, and Portland cement or lime normally provide the alkalinity to activate and accelerate these properties. On the other hand, GGBS can be added to calcium based-stabilisers such as Portland cement or lime against the expansion associated with the presence of sulphate or sulphide in soil [11]; for this reason, GGBS was only used here in mixes with the other stabilisers and not as a sole soil stabiliser.

The minimum required stabiliser dosage (per dry soil mass) for each soil was determined from Initial Consumption of Lime (ICL) tests [13]. The ICL test specifies as ICL the minimum percent calcium lime required to maintain a $\mathrm{pH}$ of 12.40 (the $\mathrm{pH}$ of $\mathrm{Ca}(\mathrm{OH})_{2}$ saturated solution at $25^{\circ} \mathrm{C}$ ); this is a measure of the amount of lime consumed by a soil due to immediate /rapid cation exchange reactions, which reduce clay mineral effective surface area and affinity for water. These rapid cation exchange reactions would thus cause a change in the swelling-shrinking characteristics of the soil and some initial strength gain. However for further strength gain in time related to the formation of calcium silicates (pozzolanic reactions), higher lime dosages, beyond the ICL would be required as widely discussed in the international literature on lime stabilisation (see e.g. [13]-[17] amongst many other). However, strength gain was not the focus of our study: we aimed at improving the swelling-shrinking behaviour of the soil. Therefore, specimens were prepared at dry stabiliser powder contents (per mass of dry soil specimen) corresponding to ICL for all stabiliser combinations (for $\mathrm{MgO}$ stabiliser ICL was determined based on the equilibrium $\mathrm{pH}$ of brucite saturated solution but a higher dosage than the ICL was used following other literature [18]). As explained above, this dosage is sufficient for modification reactions linked to cation exchange hence the reduction in the propensity of the soil to swell (to address shrinkage-swelling behaviour).

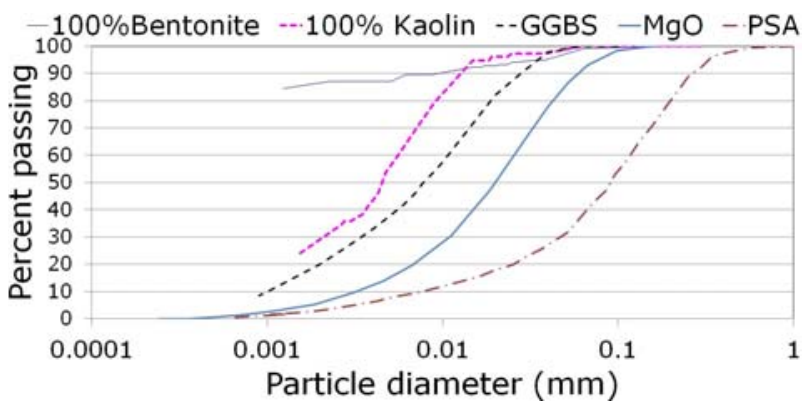

Fig. 1. Particle size distribution of all materials used.

The magnitude of swelling of an expansive soil depends on its water content and dry density. Thus, to maintain the same consistency for the different specimens (whose plasticity characteristics differ) and normalise the water content across specimens, this was set such that all specimens had a constant liquidity index of $\mathrm{IL}=-0.1$; consequently the compaction water content of specimens differed accordingly to ensure this liquidity index value. To determine the compaction water content, plasticity testing (at $24 \mathrm{~h}$ of mellowing) for each stabiliser mixture thus preceded the other tests. The results of plasticity testing are shown in Table 2. Based on these, it can be seen that lime (and its mixes) is the most effective stabiliser in terms of lowering the liquid limit and overall reducing the plasticity index (linked to the swelling potential of soils through a number of empirical relationships e.g. [19]-[22] amongst other). PSA mixes also performed well whereas $\mathrm{MgO}$ appears to have a small only effect on the plasticity characteristics of the soil. Note however that the plastic limit of chemically treated soils is affected by cementation; this attributes a tensile strength to the soil thus raising the plastic limit, The plasticity index should therefore be used with caution when referring to chemically stabilised soils, and empirical correlations between swelling 
potential and this index (developed for untreated soils) may not be appropriate for treated soils when assessing the success of treatment in terms of swelling/shrinking behaviour.

Table 1. Typical oxide composition (\%) of the stabilisers.

\begin{tabular}{|c|c|c|c|c|}
\hline & PSA & GGBS & $\begin{array}{c}\text { MgO } \\
\text { (reactive) }\end{array}$ & $\begin{array}{c}\text { Hydrated } \\
\text { Calcium Lime }\end{array}$ \\
\hline $\mathrm{SiO}_{2}$ & 19.20 & 34.68 & 1.00 & $0.70-1.00$ \\
\hline $\mathrm{Al}_{2} \mathrm{O}_{3}$ & 8.70 & 14.16 & & $0.10-0.20$ \\
\hline $\mathrm{CaO}$ & 60.70 & 38.74 & 2.00 & $95.00-97.00$ \\
\hline $\mathrm{MgO}$ & 2.80 & 7.74 & $\begin{array}{c}94.00 \\
\text { (minimum) }\end{array}$ & $1.40-0.50$ \\
\hline $\mathrm{Fe}_{2} \mathrm{O}_{3}$ & 0.50 & 0.05 & & $0.06-0.10$ \\
\hline $\mathrm{Na}_{2} \mathrm{O}$ & 0.15 & 0.46 & & \\
\hline $\mathrm{K}_{2} \mathrm{O}$ & 0.20 & 0.55 & & \\
\hline $\mathrm{SO}_{3}$ & 0.48 & 0.21 & & \\
\hline $\mathrm{P}_{2} \mathrm{O}_{5}$ & 0.17 & & & \\
\hline $\mathrm{TiO}_{2}$ & 0.20 & & & \\
\hline $\mathrm{SrO}$ & 0.09 & & & \\
\hline $\mathrm{MnO}$ & 0.02 & & & \\
\hline $\mathrm{BaO}$ & 0.04 & & & \\
\hline $\mathrm{Li}_{2} \mathrm{O}$ & 0.01 & & & \\
\hline $\begin{array}{c}\text { Refractory } \\
\text { oxides } \\
\left(\mathrm{R}_{2} \mathrm{O}_{3}\right)\end{array}$ & & & 0.70 & \\
\hline
\end{tabular}

Table 2. Plasticity characteristics before and after treatment.

\begin{tabular}{|c|c|c|c|}
\hline & $\begin{array}{c}\text { Liquid } \\
\text { limit (\%) }\end{array}$ & $\begin{array}{c}\text { Plastic } \\
\text { limit (\%) }\end{array}$ & $\begin{array}{c}\text { Plasticity } \\
\text { index (\%) }\end{array}$ \\
\hline Untreated soil & 200 & 29 & 171 \\
\hline $4 \%$ lime-treated & 110 & 64 & 46 \\
\hline 9\% PSA-treated & 138 & 59 & 79 \\
\hline $\begin{array}{c}2 \% \text { Lime-7\% } \\
\text { PSA-treated }\end{array}$ & 114 & 53 & 61 \\
\hline $\begin{array}{c}\text { 3\% Lime-3\% } \\
\text { GGBS-treated }\end{array}$ & 131 & 39 & 92 \\
\hline $\begin{array}{c}\text { 7\% PSA-3\% } \\
\text { GGBS-treated }\end{array}$ & 124 & 62 & 62 \\
\hline $12 \%$ MgO-treated & 186 & 53 & 133 \\
\hline
\end{tabular}

After mellowing for 24 hours cylindrical specimens of $75 \mathrm{~mm}$ diameter $/ 20 \mathrm{~mm}$ height were statically compacted at the required water content (determined from plasticity tests) as explained above and the same dry density of $1.3 \mathrm{~g} / \mathrm{cm}^{3}$. Compaction was performed in two equal layers of $10 \mathrm{~mm}$ height for both the oedometer and filter paper tests, using a monotonic displacement rate of $1 \mathrm{~mm} / \mathrm{min}$. The compacted specimens were then extracted from their moulds and left to cure for seven days under constant moisture curing conditions (i.e. wrapped in cling film and stored in an insulated cabinet); they were then placed on a porous stone (with a filter paper to avoid clogging of the stone) in a tray with water to absorb water through capillary rise for another seven days (i.e. 14 days of curing in total). Wetting by capillary rise from the base of the specimen used for saturation/curing is meant to represent upwards ingress of water into the stabilised soil from the water table; this was argued to be a more realistic way of representing field curing conditions after shallow mixing of stabilisers, compared to constant moisture curing [23]. During wetting the specimens were wrapped around the sides with cling film (and sealing tape) so they can be handled when softened (especially important for the untreated specimen). At the end of curing the dimensions and masses of the specimens were measured before testing which included:

(a) free swelling testing in a standard (conventional) oedometer apparatus (i.e. not suction-controlled) according to conventional testing for expansive soils (see e.g. [4]-[7]). Namely, specimens were first allowed to expand until equilibrium was reached to determine swelling strains. Subsequently, one-dimensional consolidation testing with load increments was conducted to determine swelling pressures (i.e. the pressure required to bring the volume of the specimen to its original value); finally, the specimens were unloaded to determine the swelling index $\mathrm{C}_{\mathrm{s}}$ upon unloading -as defined conventionally in Soil Mechanics, i.e. the gradient of the e- $\log \left(\sigma^{\prime}\right)$ curve, also referred to as 'rebound index' $\mathrm{C}_{\mathrm{r}}$-;

(b) the contact filter paper method (Whatman 42 paper) following procedures and calibrations developed at Imperial College, London (e.g. [24]) to assess the volumetric behaviour and water retention as a function of matric suction during drying paths of the untreated and treated soils. In addition to direct measurements of the soil volume upon drying (using callipers), the filter paper results also give the 'suction capacity', defined as $\mathrm{C}=\mathrm{DW} / \mathrm{D} \log$ (suction); for untreated soils, it is used as another measure of the propensity of the soil to change volume, as the greater the 'suction capacity' of the soil is, the higher the shrinking potential of the soil [25].

\section{Results and discussion}

\subsection{Oedometer testing}

Table 3 summarises the free swelling standard oedometer testing results in terms of swelling strain, swelling pressure and swelling (or rebound) index upon unloading, rounded to the second decimal place. The free swelling of the soils in time during the standard oedometer tests is also plotted in Fig. 2. From the table and the figure it can be seen that all chemical stabilisers have improved considerably these parameters in comparison to the respective ones of the untreated soil, and overall consistently with the plasticity results: namely lime is best to reduce swelling followed closely by PSA; MgO appears to have the lesser effect which is however still considerable as it has reduced swelling strains by $17 \%$. This concurs with literature [26] stating that the addition of an active magnesium oxide to a 
montmorillonite changes the clay into a material which is non-expansive in character, and form hydrated magnesium silicates similar to the serpentine minerals. There is little difference in the swelling pressures for each stabiliser used (all appearing to have a dramatic effect on the swelling pressure of the untreated soil). However for chemically treated soils these pressures are likely to be linked to yielding of cementation bonds rather than suppression of swelling. Thus to the Authors' opinion they should not be used in the same way as for untreated soils, to assess the success of chemically treated soils in reducing swelling characteristics. For instance, if seen in terms of swelling pressures (calculated using the free swelling standard oedometer method) $\mathrm{MgO}$ now appears to perform better that the other stabilisers but these lower pressures could in fact be an effect of weaker cementation bonding.

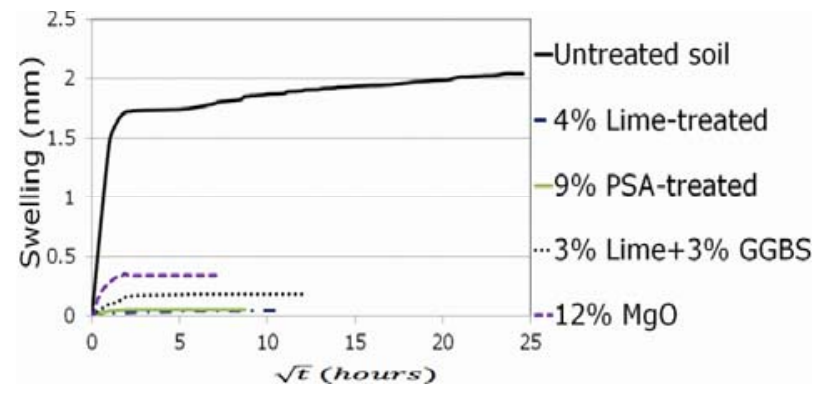

Fig. 2. Swelling vs. square root of time based on free swell oedometer tests.

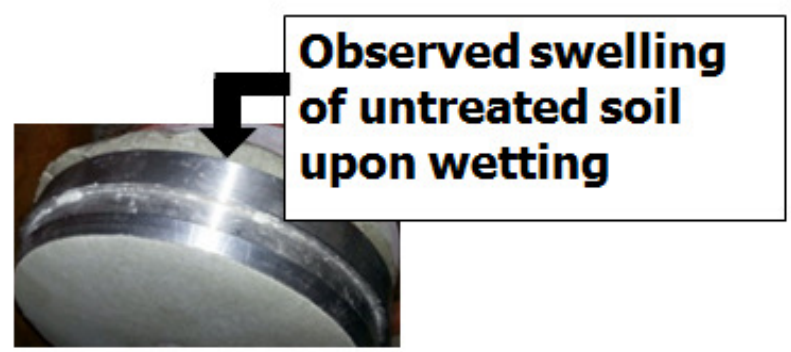

Fig. 3. Indicative photo of untreated specimen free swelling during water imbibition.

Table 3. Swelling characteristics (standard oedometer results).

\begin{tabular}{|c|c|c|c|}
\hline & $\begin{array}{c}\text { Swelling } \\
\text { strain } \\
(\%)\end{array}$ & $\begin{array}{c}\text { Swelling } \\
\text { pressure } \\
(\mathbf{k P a})\end{array}$ & $\begin{array}{c}\text { Swelling } \\
\text { index Cs }\end{array}$ \\
\hline Untreated soil & 10.2 & 905 & 0.12 \\
\hline $4 \%$ lime-treated & 0.22 & 50 & 0.02 \\
\hline $9 \%$ PSA-treated & 0.25 & 50 & 0.02 \\
\hline $\begin{array}{c}\text { 3\% Lime-3\% } \\
\text { GGBS-treated }\end{array}$ & 0.9 & 50 & 0.02 \\
\hline $\begin{array}{c}\text { 12\% MgO- } \\
\text { treated }\end{array}$ & 1.7 & 20 & 0.08 \\
\hline
\end{tabular}

\subsection{Filter paper results}

Figures 4-8 show indicative filter paper results (drying curves) in terms of water retention and volumetric behaviour of the soils during drying paths. The volumetric behaviour is consistent with the plasticity and the conventional oedometer testing results presented above, as all treated specimens had considerably lower volumetric strains upon drying (i.e. better volumetric stability) compared to the untreated soil (ca 9\%-16\% vs $50 \%$ respectively for the treated and untreated soils in the range of suctions considered) and a much narrower range of void ratios during drying (Fig 4,5,6). Overall, the range of void ratio changes after all treatments is very similar (Fig 4); it thus appears that all stabilisers caused a similar change to the skeleton stiffness and all treated soils thus react practically in the same way to the same suction changes. The apparently higher volumetric strain of the $\mathrm{MgO}$ treated soil compared to the other stabiliser treated soils (Fig 5) is predominantly due to the fact that $\mathrm{MgO}$ started drying from higher water contents (and suctions) -if plotting only for the range of suctions where strains were measured for the rest of the soils, volumetric strains of the $\mathrm{MgO}$-treated soil would be as those of other stabilisers. Note that cracking may have affected the accuracy of the volumetric measurements of the untreated soil but these are still useful indicators of the volumetric behaviour of the specimen during drying and of the considerable volume change that takes place as drying continues. Also note that at the beginning of the filter paper testing the untreated specimen (that swelled very considerably after imbibition of water by capillary rise -see Figure 3) had to be trimmed back to shape to ensure good contact with the filter paper; this trimming may have remoulded the surface of the specimen and this could have an effect on the measurements.

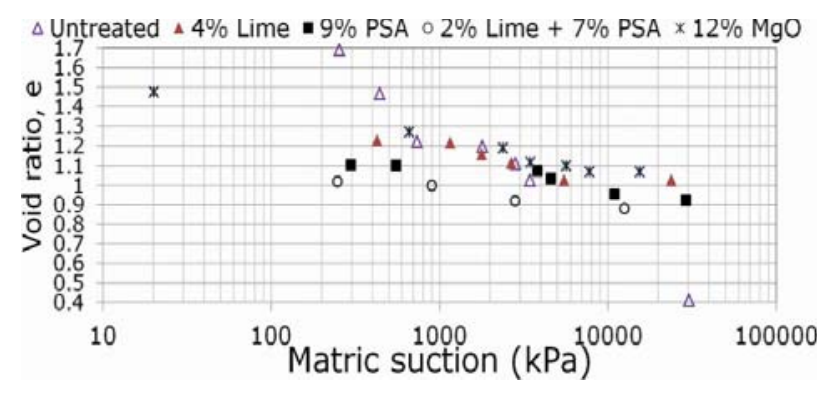

Fig. 4. Void ratio vs. matric suction relationship during filter paper testing (drying paths).

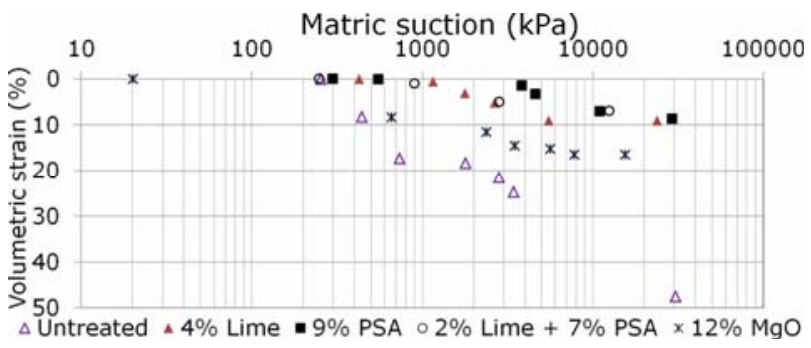

Fig. 5. Volumetric strain vs. matric suction relationship during filter paper testing (drying paths). 


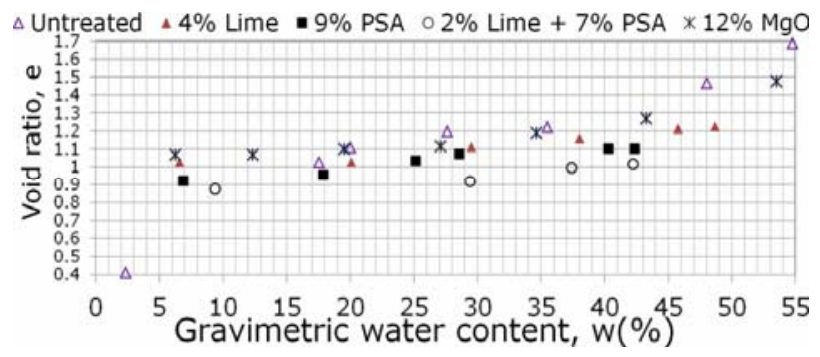

Fig. 6. Void ratio vs. gravimetric water content relationship during filter paper testing (drying paths).

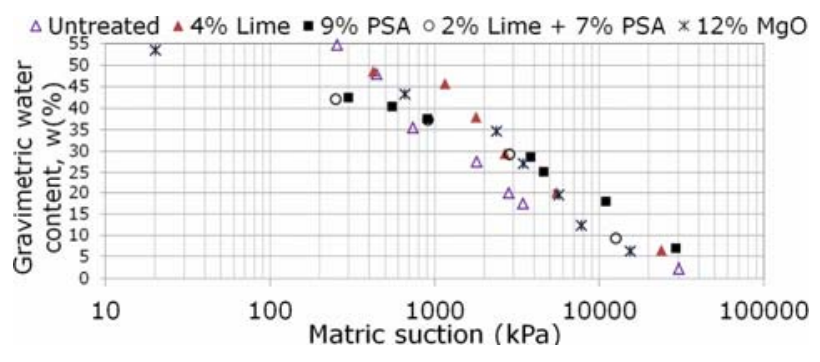

Fig. 7. Gravimetric water content vs. matric suction relationship during filter paper testing (drying paths).

Compared on the considerable effect of the stabilisers on the volumetric stability of the filter paper specimens during drying, their effect on rates of drying and consequently the suction capacity $\mathrm{C}=\mathrm{Dw} / \mathrm{Dlog}$ (suction) based on the filter paper results as shown in Fig 7 is less clear (considering also the usual scatter of the filter paper measurements); according to the results the lowest suction capacity $\mathrm{C}$ of $24-25 \%$ is found for the PSA treated soils (9\% PSA and 2\%-7\% PSA respectively); this could also be partly due to the coarser texture of the soil when PSA is added [27]. The $\mathrm{C}$ of $\mathrm{MgO}$ treated soil is found to be higher than that of the untreated soil (ca $42 \%$ ) whereas there are no clear differences between the untreated and lime treated soil suction capacity (33 vs 35 $\%$ which is too small a difference considering the low accuracy of the filter paper testing). Note the initial portion of the curve for the untreated soil shows an initial more abrupt rate of drying compared to the treated soils (bi-modal curve). To elucidate the reasons for the latter observations on the $\mathrm{C}$ values, microstructural analyses would be required in future studies. It could again be arguable whether suction capacity is an appropriate measure of assessing the improvement in terms of shrinking for treated soils, as slow rates of drying could be mostly an effect of cementation reducing the pore space rather than of clay mineralogy. Cementation can also be the reason why at higher suctions higher water contents are retained by the treated soils compared to the untreated soil for the same suction; it can also be the reason why overall for the same suctions the treated soils (which achieved higher degrees of saturation during the seven days of water curing) have higher degrees of saturation than the untreated ones (Fig. 8). Overall, the different stabiliser types used do not lead to clear differences in the relationship between degree of saturation and suction of the stabilised soils as their drying $\mathrm{S}_{\mathrm{r}}$-S curves (Fig 8) on the main coincide (especially if considering the low accuracy of filter paper method). The $\mathrm{w}-\mathrm{s}$ and $\mathrm{S}_{\mathrm{r}}$-s curves eventually tend to converge at high suctions approaching the $30 \mathrm{MPa}$ i.e. the limit of contact filter paper usable range (Fig 7-8).

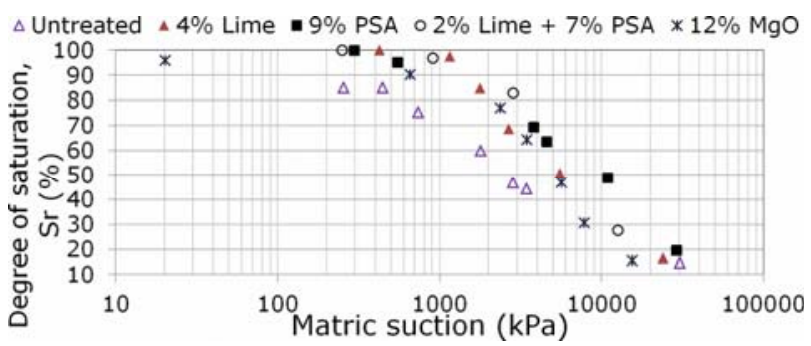

Fig. 8. Degree of saturation vs. matric suction relationship during filter paper testing (drying paths).

\section{Conclusions}

The results showed the effectiveness of innovative stabilisers used as alternatives to calcium lime for an expansive clay stabilisation. This was proven in terms of treated soil properties (plasticity characteristics, swelling strains, swelling pressures and swelling indices (based on standard oedometer tests), as well as water retention and volumetric stability as a function of suction (based on filter paper tests). In particular the performance of PSA-treated soils was very similar to that of calcium lime. Using PSA as alternative to lime has clear environmental and economic benefits: PSA has zero costs (other than transportation) as the paper sludge is anyway incinerated at the factory to reduce paper sludge waste volume. The positive findings give promise for the potential of commercial exploitation of PSA in the ground engineering/construction industry, as an alternative route to landfilling. This would result into the savings for the construction industry in terms of stabilisers. It would also help the paper making industry to meet current and emerging sustainability targets due to the considerable reduction of landfilling costs. Although less successful than PSA, reactive $\mathrm{MgO}$ (of lower energy demand for its production compared to calcium based stabilisers such as lime or cement) also showed that it can significantly improve the swelling/shrinking characteristics of soils. It can therefore also be considered as an alternative to common soil stabilisers (cement and lime) to alleviate the environmental impact of the latter.

\section{References}

1. C.W. Jones, W.G. Holtz, Civil Engineering, ASCE, 43: (49-51) (1973)

2. T.M.Petry D. N. Little, J. Mater. Civ. Eng., 14: (447-460) (2002)

3. C. Spathi Novel applications for paper sludge ash, $\mathrm{PhD}$ thesis ( Imperial College, London, 2015)

4. Z. Nalbantoglu and E.R. Tuncer Can. Geotech. J. 38: (154-160) (2001) 
5. Z. Nalbantoglu Con Build Mat 18 (377-381) (2004)

6. V. R. Murty P. H. Krishna J. Mater. Civ. Eng.,19: $(19-25)(2007)$

7. A. K. Mishra S Dhawan S M. Rao Geotech Geol Eng 26: (289-298) (2008)

8. S.K. Vanapalli, L. Lu, Int. J. Geotech. Eng., 6: (1541) (2012)

9. British Standards Institution (BSI) BS 1377 - 3: 1990 Soils for Civil Engineering Purposes (BSI, London, 1990)

10. M. Mavroulidou, Waste Manage. Res. 36: (10661072) (2018)

11. D.D. Higgins Soil Stabilisation with Ground Granulated Blastfurnace Slag (UK Cementitious Slag Makers Association (CSMA), 2005)

12. British Standards Institution (BSI) BS 1377-2:1990 (Incorporating Amendment No. 1): Methods of test for Soils for civil engineering purposes -Part 2: Classification tests (BSI, London, 1990)

13. J.L. Eades, R.E. Grim Transportation Research Board, Washington, DC Highway Research Record 139: (61-72) (1966)

14. S. Diamond and E.B. Kinter HRB Record Highway Research Board, National Research Council, 92: (83-101) Washington DC (1965)

15. F. G. Bell. Eng Geo, 42: (223-237) (1996).

16. J. Locat, M.A. Bérubé M. Choquette Can. Geotech. J 27(3): (294-304) (1990)

17. P. T. Sherwood. Soil stabilization with cement and lime. Transport Research Laboratory state-of-art review. HMSO, London (1993).

18. Y Yi, M Liska, A Akinyugha, C Unluer, A AlTabbaa, Geotech. Test. J., 36 (3)(2013)

19. H.B. Seed, R.J., Woodward, R. Lundgren, Journal of Soil Mechanics and Foundation Engineering Division ASCE, 88: (53-87) (196

20. N.V. Nayak, R.W. Clay and Clay Minerals 19: (251-261) (1971)

21. G.L. Schneider, A.R. Poor, The prediction of soil heave and swell pressures developed by an expansive clay, Research Report, No: TR-9-74, (Construction Res. Center, Univ. of Texas, 1974).

22. F.H. Chen, Foundations on Expansive Soils. (Elsevier Scientific Pub. Co., Amsterdam, New York, NY., 1975).

23. C. D. G., Rogers, D. I. Boardman, G. Papadimitriou, J. Mater. Civ. Eng, 18(2) (259-266) (2006)

24. K. Dineen, The influence of soil suction on compressibility and swelling. PhD Thesis (Imperial College, London, 1997)

25. F.A.M. Marinho, Shrinkage Behaviour of some plastic soils, $\mathrm{PhD}$ Thesis (Imperial College, London, 1994)

26. J.W.H Wang, Role of magnesium oxide in soil-lime stabilization, Retrospective Theses and Dissertations. 3830 (Iowa State Univ., 1964).
27. M. Mavroulidou, A. Ziniatis, C. Gray, et al. $15^{\text {th }}$ International Conference on Environmental Science \& Technology CEST2017, Rhodes, Greece, https://cest2017.gnest.org/taxonomy/term/523(2017) 